\title{
SERUNE KALEE DALAM UPACARA INTAT LINTO BARO DI BANDA ACEH
}

\author{
Rudi Asman \\ Jurusan Etnomusikologi Institut Seni Indonesia Yogyakarta
}

\begin{abstract}
Abstrak
Serune kalee merupakan instrumen tiup yang masih dimiliki masyarakat Aceh. Keberadaan serune kalee hingga kini digunakan dalam pelaksanaan upacara intat linto baro, pembukaan acara seremonial, penyambutan tamu, serta perayaan hari-hari besar Islam. Pelaksanaan intat linto baro menggunakan serune kalee sebagai bagian dari pelaksanaan tersebut sehingga musik yang dimainkan memiliki fungsi di dalam masyarakat Aceh. Seni pertunjukan terbagi menjadi dua kelompok, yaitu kelompok seni fungsi primer dan kelompok seni sekunder. Pendekatan sebagai payung utama adalah Etnomusikologi dibantu dengan cabang ilmu Antropologi, Sosiologi, dan Sejarah. Metodologi yang digunakan dalam penelitian ini adalah kualitatif. Pelaksanaan intat linto baro mengunakan iring-iringan sebagai tanda rombongan keluarga serta masyarakat adat kampung dari linto baro menyambung tali silahturahmi serta pengesahan terhadap pemuda dan pemudi dalam menjalankan hubungan kekeluargaan yang sah secara agama dan adat. Lagu-lagu yang digunakan adalah Pemulia Jamee serta Ranub Lampuan. Pelaksanaan tersebut merupakan moment upacara yang sakral bagi masyarakat Aceh khususnya. Fungsi musik selama pelaksanaan intat linto baro merupakan sebagai sarana upacara adat, sarana hiburan, dan sarana presentasi estetis. Pelaksanaan intat linto baro merupakan suatu pelaksanaan simbolik di dalam masyarakat yang sah secara agama dan adat seseorang melakukan perjalanan keluarga serta lagu-lagu yang dimainkan telah dikenal oleh masyarakat Aceh.
\end{abstract}

Kata kunci : serune kalee, intat linto baro.

\begin{abstract}
Seurune kalee is an inflatable instrument that is still owned by the people of Aceh. The existence of seurune kalee untill now is used in the implementation of the intat linto baro ceremony, opening ceremonial event, welcoming guest, and celebrating Islamic holidays. The implementation of intat linto baro uses seurune kalee as part of this implementation, so that the music played has function in the Acehnese comunity. Performing arts are divided into two groups, namely primary function groups and secondary groups. The main approach of this study is ethnomusicology aided by anthropology, sociology, and history. The metology used in this study is qualitative method. The implementation of intat linto baro uses accompanistment as a sign that a group of families and indigenous people from the linto baro party are connnecting with friendship and ratification of young man and young women in carrying out religious and customary family relation. The songs used are Peumulia Jamee and Ranup Lampuan. This implementation is a sacred ceremonial moment for the Aceehnese particular. Music function during the implementation of intat linto baroe is a means of traditional ceremonies, entertaiment facilities, and means of aesthetic presentation. The implementation of intat linto baro is a
\end{abstract}


simbolic implementation in a society that is religiously and customarily held by a person who initiate and the songs played are known by Acehnese comunity.

Key word: serune kalee, intat linto baro

\section{Pendahuluan}

Serune kalee merupakan instrumen tiup yang dimainkan pada prosesi arak-arakan, sunatan, pernikahan, serta penyambutan tamu besar. Penyajian serune kalee dalam suatu pertunjukan diiringi oleh instrumen tabuh (rapa'i dan geundrang) menjadi sebuah lagu iringiringan. Lagu yang dimainkan biasanya dapat sebagai iringan tari atau dimainkan secara ansambel. Selain dari itu, serune kalee juga memiliki peran dalam suatu prosesi upacara khususnya dalam upacara intat linto baro. Serune kalee merupakan permainan yang disisipkan saat tamu datang atau mengiringi kesuatu tempat khusus. Maka, serune kalee memiliki keberadaan penting saat ini dalam merayakan prosesi upacara intat linto baro.

Upacara intat linto baro merupakan salah satu tahapan dari rangkaian adat meukawen dalam masyarakat Aceh yang masih terus dipertahankan oleh masyarakat dengan berbagai variasinya. Upacara intat linto baro merupakan puncak upacara yang dinanti-nantikan karena upacara ini merupakan upacara penyambutan linto baro (mempelai pria) yang diantar ke rumah orang tua dara baroe (mempelai wanita). Intat linto baro dipandang sebagai upacara untuk menunjukkan tanggung jawab keluarga-keluarga dalam meneguhkan ikatan perkawinan. Prosesi antar mengantar pengantin dilakukan oleh keluarga, kerabat, dan masyarakat kampung linto baro. Arbi menyatakan dalam buku Tata Rias dan Upacara Adat Perkawinan Masyarakat Aceh bahwa intat linto baro adalah iring-iringan keluarga pihak laki-laki mengantar pengantin laki-laki menuju rumah mempelai perempuan. Pengantin laki-laki mendatangi kediaman mempelai wanita yang didampingi keluarga, kemudian pengantin disandingkan sejenak di pelaminan. Pengantin dan keluarga pihak pria selanjutnya menikmati jamuan makan di hadapan pelaminan, sementara tamu-tamu undangan dijamu terpisah, biasanya di luar rumah atau halaman. Pelaksanaan upacara intat linto baro merupakan hal terpenting dalam 
pelaksanaan hukum adat di Aceh, sehingga pelaksanaan tersebut melibatkan banyak orang agar menyaksikan suatu pasangan memiliki hubungan yang sah di dalam masyarakat.

Berdasarkan uraian di atas, serune kalee telah melalui perjalanan panjang di tengah-tengah masyarakat, serta memiliki fungsi di tengah-tengah masyarakat. Selain itu, serune kalee sebagai iring-iringan intat linto baro pada saat ini masih terus dipentaskan oleh masyarakat dan seniman Aceh. Penelitian terhadap pelaksanaan upacara intat linto baro telah dilakukan oleh peneliti-peneliti sebelumnya. Namun, serune kale juga memiliki peran serta keterkaitan dengan fungsi selama pelaksanaan upacara tersebut. Penelitian kali ini menjadi sangat penting dilakukan. Serune kale yang memiliki fungsi serta menjadi bagian simbolik dan memiliki makna di dalam upacara intat linto baro untuk didokumentasikan dalam penelitian kali ini.

\section{Upacara Pernikahan Masyarakat}

\section{Aceh}

Intat linto baro atau dalam bahasa Indonesianya memiliki arti intat (antar), linto (pengantin laki-laki), baro (baru). Intat linto baro memiliki makna mengantar pengantin laki-laki baru ke kediaman dara baro (pengantin wanita baru). Intat linto baro merupakan bagian dari rangkaian prosesi perkawinan yang dilakukan setelah akad nikah atau ijab kabul (meugatib). Masyarakat Aceh memiliki pandangan, pernikahan dianggap belum sah sebelum melakukan tradisi yang satu ini. Intat linto baro (pengantin Pria) merupakan pesta peresmian di rumah orang tua dara baro (pengantin wanita). Pelaksanaan intat linto baro ini juga sering disebut dan dipahami dengan Raja si uroe (raja sehari). Prosesi upacara intat linto baro merupakan ujian yang harus dijalani orang yang akan menjadi anggota suatu perkumpulan, suku, kelompok umur, dan strata sosial, hal ini disebut dengan inisiasi.

\section{Prosesi Pelaksanaan Intat Linto Baro}

1. Iring-Iringan Linto Baro

Iring-iringan intat linto baro merupakan acara awal dimulainya pelaksanaan upacara intat linto baro. Salah satu aspek yang penting diperhatikan dalam upacara adat intat 
linto adalah menyangkut dengan iringiringan rombongan intat linto baro. Barisan pertama merupakan rombongan penabuh rapa' $i$ dan peniup serune kalee. Barisan paling depan adalah barisan penabuh rapa'i dan serune kalee. Lagulagu yang dimainkan adalah lagu Pemulia Jamee atau Ranub Lampuan. Barisan paling depan berjalan tukang musik atau pemain musik (geundrang dan serune kalee). Jumlah pemain musik selama iring-iringan tidak memiliki ketentuan yang tetap. Pemain musik serune kalee yang dianggap ideal terdiri dari satu orang peniup serune kalee, dua orang pemain rapa' $i$, satu orang pemain geundrang.

Barisan kedua merupakan para tokoh adat ureung inong. Barisan ini berperan terdiri dari beberapa orang tokoh adat perempuan yang membawa batee ranub (cerana), setiba di depan pintu masuk rumah dara baro akan melakukan penyerahan prosesi penyerahan batee ranub (cerana). Ranub yang di dalamnya berisi biji pinang, gambir dan sedikit kapur ranub diyakini mampu memperkuat gusi pada gigi. Masyarakat Aceh meyakini ranub memiliki nilai yang tinggi dan berperan penting khususnya pada upacara pertunangan dan perkawinan pada masyarakat Aceh. Selain dari itu juga dapat menjaga kesehatan tubuh.

Ranub merupakan hal yang sangat penting bagi masyarakat Aceh. Pentingnya ranub dalam kehidupan sehari-hari terdapat di dalam syair Aceh.

"Asalammualaikum jame baroe troh tamong jak piyoh duk ateuh tika.

Salaeum kamoe bri bapak neusambot bek neduek ulua tika.

Mulia mulia wareh ranub lampuan mulia mulia rakan mameh suara.

Ranub kamoe bri bapak neu pajoh hana kamo boh racon ngon tuba.

Racon ngen tuba tan lon ba sajan salah bak tuhan han ampon desya."

Arti dan makna syair di atas sebagai berikut.

(Asalammualaikum tamu telah sampai silahkan masuk ke dalam rumah dan duduk di atas tikar yang telah kami sediakan. Makna yang terkandung dalam syair di atas Asalammualaikum merupakan salam yang disampaikan seseorang kepada yang sedang bertemu atau tamu ke tempat seseorang, serta mempersilahkan para tamu untuk masuk ke dalam rumah yang telah kami persiapkan dan menjamu kedatangan anda (tamu) dan duduk di atas tikar sebagai tanda keiklasan kami menerima anda di rumah kami.

Salam yang kami sampaikan wajib dibalas dan jangan duduk di luar pekarangan rumah. Salam yang 
disampaikan merupakan hal yang wajib hukumnya dalam Islam untuk menjawab wa'alaikum salam hal tersebut merupakan perintah agama. Tamu bagi orang Aceh sangat dimuliakan sehingga apabila berlama-lama berdiri di depan pintu menjadikan aib bagi pemilik rumah yang di kunjunggi.

Memuliakan saudara (tetangga) dengan ranub dalam cerana memuliakan tamu dengan suara lemah lembut. Menyajikan ranub dalam cerana merupakan salah satu memuliakan tamu dan sanak saudara, beserta bertutur sapa dengan lemah lembut agar kenyamanan dapat dirasakan selama berkunjung.

Ranub yang kami sajikan silahkan bapak-bapak (tamu) cicipi tidak kami taruh racun dan meracuni hadirin sekalian. Ranub yang telah disajikan janganlah berprasangka ada racun atau pemilik rumah untuk meracuni tamunya silahkan menikmatinya suguhan pemilik rumah dan jangan khawatir akan keberadaan anda (tamu) kami jamin akan keselamatan serta pelayanannya.

Racun dan meracuni bukan salah kami seluruhnya serta salah tuhan tidak mengampuni dosa. Ungkapan niat baik dengan mengatakan ketulusan hati dalam menerima tamu, beserta kesadaran tuan rumah berdasarkan nilai-nilai ilahiyah atau hakikat kebenaran.)

\section{Barisan ketiga diisi oleh kalangan}

tokoh adat kampung (Ureung Tuha Gampong). Barisan ini merupakan barisan ureung tuha gampong, yang terdiri dari kheucik, imuem menasah, tuha peut, tokoh-tokah adat gampong dan ureng seumapa. Barisan keempat adalah linto baro dan pengapet linto baro. Linto baro berada diantara peungapet rombongan yang biasanya terdiri dari para pemuda, teman-teman dari linto baro. Linto baro ditempatkan pada posisi agak tersembunyi yakni di tengah-tengah para peungapet linto baro dan dipayungi dengan payung kuneng (kuning) oleh salah seorang pengapet linto. Barisan kelima merupakan idang peuneuwo. Barisan ini sebagai pembawa ideung peneuwoe dan bunggong jaroe. Ideung peneuwoe dan bunggong jaroe yang dimasukkan dalam talam dan ditutup dengan sangge dengan motif dan corak warna warni. Dahulu ideung diusung oleh kaum perempuan kampung yang telah ditentukan. Pembawa idang peneuwoe dilakukan oleh para pemuda. Idang peunewo dibawa oleh rombongan linto selama iring-iringan, selanjutnya idang peunewo akan disambut oleh dari pihak dara baro apabila telah diberikan aba-aba dari seumapa.

Barisan keenam rombongan ureung inong. Rombongan ini sebagai pengantar linto baro dan biasanya pengantar linto baro merupakan perempuan dan berjalan belakang linto baro. Rombongan ini terdiri dari 
keluarga inti dari linto baro tidak termasuk dari rombongan undangan pelaksanaan kenduri. Jumlah yang terdapat dalam barisan ini dapat terdiri dari 10-15 orang. Barisan ketujuh rombongan ureung agam. Barisan ini merupakan rombongan laki-laki yang berjalan di belakang barisan. Rombongan ureung agam merupakan kerabat dari linto, atapun paman dari pihak ayah atau lbu linto baro.

\section{Serah Terima Linto Baro}

Linto baro memasuki dalam pekarangan rumah orang tua sang dara baroe beserta pengantar, orang-orang dari kampung itu yang berdiri berbarisbaris kiri kanan telah menunggu untuk menerima para tamu. Linto baro menyimpan lintonya di belakang pengantar. Tatkala mereka sudah sampai di pekarangan rumah dara baro, kini orang memulai pelaksanaan adat selanjutnya. Tugas para pengantar linto baro hanya di gerbang penyambutan, kemudian menukar batee ranub sebagai tanda serah terima linto baro ke pihak dara baro. Kemudian, pihak mempelai wanita akan mengambil alih mempelai prianya untuk kemudian dilanjutkan dengan prosesi berikutnya seperti peusijuek atau tepung tawar.

\section{Seumapa}

Berikut contoh seumapa yang dilakukan selama prosesi intat linto baro Linto baro:

"Assalamualaikum warahmatullahi wabarakatuh

Saleum kamoe brie nibak uroe nyoe ke ureng Lamno digampong Leupe Matang

Kamoe jak jioh wahe adun ngon adoe dari nanggroe Tiro di Pidie Lama

Kamoe troh keuno na inong na agam na sebagian aneuk dara

$\mathrm{Na}$ pemuda-pemuda yang ganteng ruman na sebagian inong janda

\section{Linto baro:}

Assalamualaikum warahmatullahi wa barakatuh

Salam kami sampaikan pada hari ini ke orang Lamno di kampung Leupe Matang

Kami pergi jauh wahai abang dan adik, dari negeri Tiro di Pidie Lama

Kami telah sampai di sini ada wanita ada lelaki ada juga sebagian anak dara Ada pemuda-pemuda yang ganteng wajahnya dan sebagian wanita janda

Berdasarkan uraian di atas, mempelai pria akan memasuki ke rumah mempelai wanita beserta dengan rombongan disambut dengan sapaan pantun (seumapa) oleh perwakilan tuan 
rumah dan pihak tamu wajib membalas pantun tersebut. Hal tersebut sebagai tegur sapa dengan mengunakan bahasa yang khusus yang telah menjadi bagian dari adat orang Aceh dalam mengunjungi ke tempat orang lain.

\section{Tari Ranub Lampuan}

Tari Ranub Lampuan merupakan penyambutan intat linto baro. Tari ini terdiri dari 7 orang penari dan diiringi oleh pemain serune kalee. Tarian ini memiliki durasi selama 5 menit. Selama penampilan tari linto baro diberikan kursi untuk menyaksikan persembahan tersebut dan rombongan lain menunggu sambil berdiri di belakang linto baro, akhir dari pertunjukan ini linto baro akan disuguhkan sirih untuk diambil sebanyak linto baro inginkan. Selanjutnya, linto baro akan memberikan amplop berisikan uang kepada penari sebagai tanda terima kasih telah menjamu kedatangan rombongan linto baro.

\section{Peusijuek}

Peusijuek sesungguhnya merupakan ungkapan doa-doa dan puji pujian dari orang tercinta kepada sang
Khalik dengan harapan sesuatu tersebut selalu diberkahi oleh Allah SWT. Peusijuek bermakna sejuk, menyegarkan, tenang, menghibur, dan terhindar dari pengaruh bencana. Peusijuek berasal dari kata sejuk yang memiliki lawan kata dari su'um atau panas. Prosesi ini bertujuan agar pengantin dalam menjalani bahtera rumah tangga dilalui dengan kondisi sejuk atau tenang. Peusijuek dilaksanakan dimulai dari pihak keluarga dara baro (pengantin wanita) kemudian dilanjutkan oleh keluarga linto baro dan diakhiri dengan memberikan hadiah berupa uang atau barang berharga lainnya. Jumlah orang yang mempesijuek (teumentek) harus berjumlah ganjil, biasanya terdiri dari tiga orang atau tujuh orang. Tradisi Peusijuek di Aceh sudah berlangsung lama dari dahulu hingga kini masih menyatu dengan masyarakat Aceh. Pesiujuek merupakan suatu acara tradisi penyambutan sesuatu yang baru dengan harapan dapat memperoleh keberkahan dan terhindar dari berbagai marabahaya. Acara pernikahan (tueng dara baro, intat linto baro), dalam tradisi Aceh akan melakukan acara peusijuek (dipeusijuek). 


\section{Metode Penelitian}

Pendekatan sebagai payung utama adalah Etnomusikologi dibantu dengan cabang ilmu Antropologi, Sosiologi, dan Sejarah. Metodologi yang digunakan dalam penelitian ini adalah kualitatif

\section{Hasil dan Pembahasan}

\section{Serune Kalee: Lagu-lagu dan Fungsinya}

Instrumen serune kalee dikenal dan tersebar di wilayah masyarakat Aceh Utara, Pidie, Lhoksumawe, Aceh Besar, dan Aceh Barat. Hasil pengamatan selama di lapangan ditemukan bahwa serune kalee merupakan dua kata terpisah terdiri dari serune dan kalee. Kata serune pada umumnya digunakan penyebutan alat tiup yang menggunakan lidah (reed) dan menggunakan daun lontar sebagai sumber bunyi atau bambu. Penyebutan kata serune banyak digunakan oleh masyarakat nusantara seperti, serune (Mandailing), sarune bolon (Batak Toba), sarunai kayu (Padang), sarunai (Riau) atau serune (Sumbawa). Meskipun, asal kata serune ini belum ada yang memastikan apakah berdasarkan dari perbendaharaan kata
Melayu. Namun, masyarakat Turki memiliki instrumen yang sama dengan penyebutan dengan Zurna dan masyarakat Kashmir menyebut instrumen tersebut dengan Sor-nai. Berdasarkan dari catatan bahwa Aceh merupakan daerah yang banyak didatangi oleh para pendatang asing yang juga menetap sehingga alat tersebut ada perubahan penyebutan dengan bahasa Melayu dan instrumen yang diperkenalkan oleh para pendakwah Islam. Berdasarkan sumber buku kamus Aceh menjelaskan bahwa, Serune (serunai) memiliki arti seruling padi. Kalee dalam bahasa Aceh memiliki arti umpama bernyanyi atau menari dengan berbagai cara (jakalee). Maka, serune kalee memiliki arti seruling bernyanyi atau menari.

Berdasarkan penjelasan di atas, penamaan serune kelee diduga memiliki percampuran pangucapan bahasa yang dibawa oleh bangsa timur saat memasuki Aceh. Namun, masyarakat Aceh telah menyebut serune kalee sebagai seruling bernyanyi atau menari. Walaupun, seorang dari pelaku serune memiliki kisah yang berbeda dalam penamaan serune kalee. Namun, sampai saat ini belum ada yang dapat membuktikan 
kebenaran kisah tersebut. Serune kalee dapat dipahami sebagai instrumen serta juga kelompok bermain musik secara ansambel.

\section{Lagu-lagu Serune Kalee dalam Intat}

\section{Linto Baro}

1. Tema Lagu-lagu Prosesi Iringiringan dalam Intat Linto Baro Tema- tema yang sering digunakan dalam permainan serune kalee adalah tema yang menyenangkan optimistis dan yang menimbulkan rasa enak. Penglompokan tema serune kalee memiliki kesamaan secara gaya, dan tehnik, yang sering digunakan dalam komposisi tari atau syair di Aceh pada umumnya.

Tema optimistis: lagu-lagu yang biasa digunakan untuk mengiringi tari Ranub Lampuan, Pemulia Jamee, Drop Darut, dan Nadan. Tema optimistis sering dimainkan juga tanpa menggunakan tarian pada saat penyambutan tamu besar, menyambut tamu kawin, wisuda dan bersifat formal. Tema optimistis ini lebih cendrung memainkan suasana irama musik lebih hikmat, berwibawa, bersahaja, beretika, sopan santun, merayakan dan mengungkapkan keriangan. Tema ini sendiri merupakan untuk menyapa atau menegur kepada tamu, kelompok, individu. Tema ini menggunakan irama musik masih bersumber dari lagu-lagu Aceh diterjemahkan mengunakan melodi serune kalee. Musik optimistis memiliki kecendrungan mengunakan nada awal dari lubang 3 atau 4 dan terkadang penanda akhir lagu memainkan lubang atas (Lubang 6) dan kembali kelubang 3 atau 4, dan kecendrungan dimainkan pada down stroke.

Lagu-lagu yang dimainkan selama iring-iringan menggunakan lagu Pemulia Jamee. Lagu ini telah dikenal oleh masyarakat sebagai musik tarian sekaligus syair Aceh yan telah berkembang dimasyarakat. Pemain serune kalee sengaja memainkan lagu tersebut karena lagu tersebut secara syair menjelaskan seseorang ingin menikahi seorang gadis dengan cara menggunakan kata kiasan. Kata kiasan tersebut menggunakan ayah sebagai perantara untuk meminang seorang gadis. Lagu Pemulia Jamee telah dikenal oleh masyarakat yang sesuai dengan keadaan seorang linto baro telah berhasil menikahi seorang wanita yang telah 
kehendaki. Selanjutnya, lagu Ranub Lampuan merupakan iringan tari yang dikenal masyarakat untuk memuliakan tamu. Rombongan iring-iringan menunggu selesainya prosesi tari tersebut. Tari tersebut terdapat gerakangerakan yang dimengerti oleh masyarakat sebagai tanda untuk membawa sifat-sifat kebaikan dalam jamuan dan membuang sifat-sifat buruk tidak dibawa dalam acara tersebut. Gerakan tersebut sebagai lambang agar dapat menghubungkan ikatan persaudaraan lebih baik.

\section{Interval}

Nada dasar serune kalee memiliki varian yang berbeda-beda. Kecendrungan nada pada serune kalee merupakan micro tonal atau nada tidak sampai diantara nada penuh dan masih kurang dari nada diantara. Penyeteman nada serune kalee dibuat dengan cara manual atau sesuai laras lokal (terroir) pembuat lubang nada skala melodi, sehingga sulit mendapatkan nada pitch sempurna. Namun, tangga nada yang digunakan berasal dari tangga nada diatonis minor. Tangga nada yang terdapat pada serune kalee kurang lebih diantaranya adalah. $\begin{array}{lllllllll}1 & 2 & 3 & 4 & 5 & 6 & 7 & 8 & 9\end{array}$

(Tutupan lubang dari bawah ke atas)

Fa le la si do re mi fa sol ( interval)

$\begin{array}{lllllllll}4 & 5^{\#} & 6 & 7 & 1 & 2 & 3 & 4 & 5\end{array}$

(Notasi angka)

$$
\begin{array}{llllllll}
1^{1 / 2} & 1 / 2 & 1 & 1 / 2 & 1 & 1 & 1 / 2 & 1
\end{array}
$$

(Jarak interval)

3. Transkripsi dan musik Ranub Lampuan
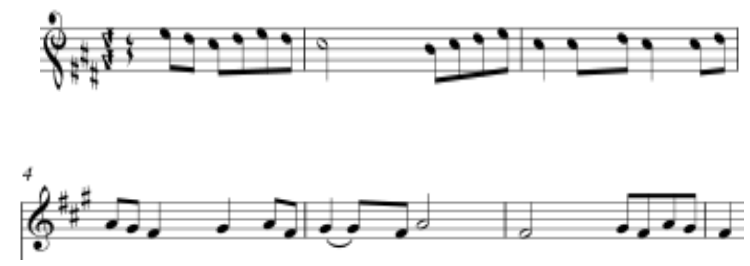

Melodi lagu ini dimainkan secara berulang-ulang oleh pemain serune kalee. Permainan tergantung oleh peniup menambahkan grenek dalam setiap permainan agar lagu tersebut tidak bosan untuk didengar oleh penonton. Kalimat melodi pada bar ke 6 kembali ke bar 1 tanpa menggunakan tanda diam, karena tanda diam telah di gantikan oleh nada la (6) dan menyambung kalimat selanjutnya. 


\section{Fungsi Serune Kalee dalam}

\section{Pelaksanaan Intat Linto Baro}

Iring-iringan serune kalee dalam

pelaksanaan intat linto baro tidak sebagai fungsi ritual karena kesenian ritual yang berkembang dikalangan masyarakat yang tata kehidupanya mengacu pada nila-nilai budaya agraris, serta masyarakat yang memeluk agama dalam kegiatan-kegiatan ibadahnya sangat melibatkan seni pertunjukan. Namun, masyarakat Aceh tidak menganggap kesenian tersebut sebagai kesenian ritual karena masyarakat Banda Aceh merupakan masyarakat yang memiliki pola hidup masyarakat pesisir seperti yang diungkapkan oleh Jacob Sumardjo bahwasanya masyarakat pesisir memiliki pola kehidupan dan semboyan-semboyan yang berkisahkan tentang raja-raja seperti yang berkembang terdapat pepatah " raja adil raja disembah, raja lalim raja disangah" hanya berlaku untuk masyarakat berpola empat. Pelaksanaan intat linto baro disebut juga perayaan raja si uroe (raja sehari). Selama prosesi berlangsung merupakan adat yang berasal dari kata 'adlah (kebiasaan). Adat ini merupakan perilaku masyarakat Aceh sebagai perayaan atau upacara adat dan tidak memiliki keterkaitan dengan kewajiban dalam hukum syariah, melainkan kebiasaan masyarakat Aceh menjalankan adat di dalam masyarakat.

\section{Sarana Hiburan}

Pertunjukan serune kalee sebagai hiburan pribadi setiap penikmat memiliki gaya pribadi sendiri-sendiri serta sikap rombongan yang terlibat memiliki kesan tersendiri dalam suasana khidmat tersebut. Selama pertunjukan berlangsung tidak ada aturan yang ketat untuk menunjukan ekspresi wajah dan sikap khusus, para rombongan memiliki kesan tersendiri selama prosesi berlangsung. Rombongan yang terlibat sebagai penikmat bisa mengikuti irama tari serta merespon, kenikmatan pribadi akan tercipta. Selama prosesi berlangsung seluruh rombongan terlibat sebagai bagian dari pertunjukan tersebut sehingga serune kalee merupakan pertunjukan kesenian yang bersifat hiburan pribadi dan memiliki fungsi primer di dalam pelaksanaan prosesi intat linto baro. 
Sarana Presentasi Estetis

Pemain serune kalee dituntut untuk menyajikan musik yang sangat baik agar dapat didengarkan selama prosesi terserbut menjadi berkesan. Selain dari itu para penari menggunakan kostum yang sangat rapi dan berhiaskan mahkota sebagai tanda menunjukan kesiapan menjamu rombonggan linto baro merupakan hal yang sanggat sepesial pada pelaksanaan upacara tersebut. Kesan indah yang ditampilkan membuat wajah para pendatang menjadi tersenyum beserta dengan sapaan terhadap penari. Sarana estetis mendatangkan kesan indah yang membuat rombongan merasa nyaman selama menggikuti prosesi adat. Kesan kemeriahan yang diciptakan oleh pemain serune kalee beserta penari membuat para rombongan menjadi kagum atas persiapan dari pihak dara baro mempersiapkan kedatangan rombongan linto baro.

\section{Simpulan}

Lagu-lagu yang digunakan selama iring-ringan menggunakan lagu Ranub Lampuan atau Pemulia Jamee.
Lagu-lagu tersebut dimainkan karena masyarakat Aceh telah mengenal lagu tersebut sehingga dapat membuat suasana pelaksanaan prosesi tersebut menjadi khidmat. Meskipun, lagu-lagu tersebut dikenal oleh masyarakat sebagai musik iringan tari namun tidak menguragi esensi dari pelaksaanaan.

Kesenian serune kalee merupakan kesenian Aceh yang telah mentradisi di dalam adat masyarakat Aceh. Kesenian yang hidup di dalam masyarakat Aceh tersebut memiliki fungsi sabagai sarana upacara adat, sarana hiburan dan sarana presentasi estetis. Sarana upacara adat merupakan hal yang sangat disukai sebagai pelaksanaan hukum adat, sarana hiburan merupakan hal yang bersifat menyenangkan selama prosesi upacara intat linto baro. Sarana presentasi estetis merupakan kegiatan yang mendatangkan kenikmatan indrawi selama prosesi berlangsung. Hal tersebut, menjadikan kesenian serune kalee merupakan hal yang primer di dalam pelaksanaan upacara intat linto baro. Upacara intat linto baro tersebut merupakan puncak dari pelaksanaan adat meukawen sehingga upacara tersebut sebagai simbolik seseorang pemuda dan pemudi 
menuju bahtera rumah tangga dan menjadi bagian yang sah di dalam lingkungan masyarakat secara agama dan adat. Upacara intat linto baro suatu suasana kemeriahan, rasa syukur, menyambung tali silahturahmi serta keberhasilan seorang pemuda menggambil tanggung jawab dalam kehidupan sehari-hari maka serune kalee memiliki peran besar dalam menyemarakan dan menyukseskan prosesi acara tersebut.

\section{Daftar Pustaka}

Bakar, Aboe. 2001. Kamus Bahasa AcehIndonesia. Jakarta: Balai Pustaka.

Banoe, Pono. 2003. Kamus Musik. Yogyakarta: Kanisius.

Darmawan, Hendro. 2013. Kamus Ilmiah Populer. Yogyakarta: Bintang Cemerlang.

Daud, Syamsudin. 2014. Adat Meukawen (Adat Pernikahan Aceh). Aceh: Majelis Adat Aceh.

Hadi, Amirul, 2010. Aceh Sejarah Budaya dan Tradisi. Jakarta: Yayasan Obor Indonesia,.

Hoesin, Moehammad. 1970 Adat Atjeh. Aceh : Dinas Pendidikan dan Kebudayaan Prov Daerah Istimewa Aceh.
Hood, Made Mantle. 2014. "Menuju Penerapan Musical Terroir Konteks Melemahnya Laras Lokal", dalam, St. Hanggar budi Prasetyo dan Agnes Widyasmoro,ed., prosiding seminar Nasional Festifal Kesenian Indonesia Ke 8 "Spirit of The Future: Art for Humanizing" Yogyakarta: BP ISI Yogyakarta.

Isjkarim. 1981. "Kesenian Tradisional Aceh". hasil lokakarya 4/8 januari di Banda Aceh, Departemen Pendidikan dan Kebudayaan, Kantor Wilayah Propinsi Daerah Istimewa Aceh.

Kartomi, Margaret. 2012. Musical Journeys in Sumatra. United Stateof America: University of Illinois press.

Kuntowijoyo. 2006. Budaya dan Masyarakat : Edisi Paripurna. Yogyakarta: Tiara Wacana.

Liliweri, Alo. 2014. Pengantar Studi Kebudayaan. Bandung: Nusa Media.

Muntasir, Azhar. 2010. Adat Perkawinan Etnis Aceh. Banda Aceh: Pemerintahan Aceh Dinas Kebudayaan dan Pariwisata

Murtala. 2009. Yuslizar dan Kreasi yang Mentradisi. Banda Aceh: No Goverment Individual.

Nettl, Bruno. 2012. Teori dan Metodologi dalam Etnomusikologi., terj. Nathalian H.P.D Putra. Jayapura: Jayapura Center Of Music. 
Jurnal Etnomusikologi

Prier S.J, Karl Edmund. 2006. Sejarah Musik Jilid I. Yogyakarta: Pusat musik Liturgi.

Reid, Anthony. 2011. Мепији Sejarah Sumatra Antara Indonesia dan Dunia. Jakarta: Yayasan Obor Indonesia.

Setia Budi, Anton. 2001. "Teknik Dasar Bermain Serune Kale" Skripsi untuk mencapai derajat Sarjana S-1 pada Program Studi Pendidikan Sendratasik, Fakultas Keguruan dan Ilmu Pendidikan, Universitas Syiah Kuala, Banda Aceh.

Soedarsono, R.M. 2002. Seni Pertunjukan Indonesia di Era globalisasi. Yogyakarta: Universitas Gadjah Mada.

Sumardjo, Jacob. 2006. Estetika Paradoks. Bandung : Sunan Ambu Press. 